ARTICLE

https://doi.org/10.1038/s41467-019-13712-2

\title{
Multistaged discharge constructing heterostructure with enhanced solid-solution behavior for long-life lithium-oxygen batteries
}

Shu-Mao Xu (1) ${ }^{1}$, Xiao Liang ${ }^{1}$, Xue-Yan Wu${ }^{1}$, Shen-Long Zhao ${ }^{2}$, Jun Chen (1) ${ }^{2 \star}$, Kai-Xue Wang ${ }^{1 \star}{ }^{1 \star} \&$ Jie-Sheng Chen ${ }^{1 \star}$

Inferior charge transport in insulating and bulk discharge products is one of the main factors resulting in poor cycling stability of lithium-oxygen batteries with high overpotential and large capacity decay. Here we report a two-step oxygen reduction approach by pre-depositing a potassium carbonate layer on the cathode surface in a potassium-oxygen battery to direct the growth of defective film-like discharge products in the successive cycling of lithium-oxygen batteries. The formation of defective film with improved charge transport and large contact area with a catalyst plays a critical role in the facile decomposition of discharge products and the sustained stability of the battery. Multistaged discharge constructing lithium peroxide-based heterostructure with band discontinuities and a relatively low lithium diffusion barrier may be responsible for the growth of defective film-like discharge products. This strategy offers a promising route for future development of cathode catalysts that can be used to extend the cycling life of lithium-oxygen batteries.

\footnotetext{
${ }^{1}$ Shanghai Electrochemical Energy Devices Research Center, School of Chemistry and Chemical Engineering, Shanghai Jiao Tong University, Shanghai 200240, China. ${ }^{2}$ Department of Bioengineering, University of California, Los Angeles, CA 90095, USA. *email: jun.chen@ucla.edu; k.wang@sjtu.edu.cn; chemcj@sjtu.edu.cn
} 
$\mathrm{i}-\mathrm{O}_{2}$ batteries have triggered worldwide interest in energy storage system in the last decade owing to an increasing demand for high-density energy storage for electric vehicle applications $^{1-3}$. However, the wide-range application of this battery technology is likely to be shadowed by its low round-trip efficiency, poor cycle life, and low power density ${ }^{3,4}$. Limited electron transfer in bulky $\mathrm{Li}_{2} \mathrm{O}_{2}$ discharge product is one of the main reasons for the difficulty to completely decompose large particles of $\mathrm{Li}_{2} \mathrm{O}_{2}$ with sufficiently fast charge transfer ${ }^{4-6}$ and sustainably react at the electrodes with superior durability ${ }^{7,8}$. Directing the growth of onedimensional rod-like ${ }^{6}$ or film-like $e^{4,9-12}$ amorphous discharge products instead of bulky toroid $\mathrm{Li}_{2} \mathrm{O}_{2}$ with enhanced charge transport is extensively adopted to accelerate and sustain the electrode reactions for high-performance $\mathrm{Li}-\mathrm{O}_{2}$ batteries. In addition to the morphology manipulation, the introduction of defects by element doping $^{13-16}$ is also utilized to enhance the charge transport and expedite the oxygen evolution reaction kinetics.

Off-stoichiometric $\mathrm{Li}_{2-x} \mathrm{O}_{2}$ phase $(0<x<1)$ with $\mathrm{Li}$ vacancies was predicted to be metallic with enhanced electron conductivity by first-principles calculations ${ }^{13,17,18}$. The $\mathrm{Li}$-deficient $\mathrm{Li}_{2-x} \mathrm{O}_{2}$ is generally believed to form during charge upon the extraction of $\mathrm{Li}^{+}$from crystalline $\mathrm{Li}_{2} \mathrm{O}_{2}$ with the release of electrons ${ }^{19-21}$. The formation of $\mathrm{Li}_{2-x} \mathrm{O}_{2}$ with faster decomposition rate than commercial $\mathrm{Li}_{2} \mathrm{O}_{2}$ powder implies enhanced charge transport and facile decomposition of electrochemically grown $\mathrm{Li}_{2-x} \mathrm{O}_{2}{ }^{22,23}$. Therefore, tailoring the formation of off-stoichiometric $\mathrm{Li}_{2-x} \mathrm{O}_{2}$ with enhanced charge transport by surface modification is of great significance to achieve $\mathrm{Li}-\mathrm{O}_{2}$ batteries with high cycling stability. Inspired by favorable $\mathrm{Li}$ transport through $\mathrm{Li}_{2} \mathrm{CO}_{3}$ solid electrolyte interphase (SEI) films in typical Li-ion batteries with long-term stability ${ }^{24-26}$, surface engineering of a coating layer with feasible $\mathrm{Li}^{+}$interstitials as diffusion carriers is proposed to protect the surface of cathode catalysts and induce the formation of defective discharge products for long-life $\mathrm{Li}-\mathrm{O}_{2}$ batteries.

Herein, a two-staged discharge approach to construct $\mathrm{Li}_{2} \mathrm{O}_{2}$ based heterostructure paves a way to enhance charge transport in discharge products and improve the durability of $\mathrm{Li}-\mathrm{O}_{2}$ battery. Considering the insulator nature of most $\mathrm{Li}_{2} \mathrm{CO}_{3}$ products ${ }^{27,28}$, a layer of $\mathrm{K}_{2} \mathrm{CO}_{3}$ instead of $\mathrm{Li}_{2} \mathrm{CO}_{3}$ is first deposited on the cathode surface in a $\mathrm{K}-\mathrm{O}_{2}$ battery. Successive discharge in $\mathrm{Li}-\mathrm{O}_{2}$ battery epitaxially deposits $\mathrm{Li}_{2} \mathrm{O}_{2}$ discharge products on the exterior surface of $\mathrm{K}_{2} \mathrm{CO}_{3}$, inducing the formation of built-in field around the junction and promoting the charge transfer and the formation of defects at the interface/surface ${ }^{29-31}$. Moreover, after multistaged discharge, tailored film-like instead of large toroidal discharge products is deposited on the surface of cathode, suppressing the passivation/clogging of the cathode. The resulting PVP-C@LDO cathode can be operated in $\mathrm{O}_{2}$ over 70 cycles (over 175 d) without distinct capacity decay at a limited specific capacity of $3000 \mathrm{mAh} \mathrm{g}^{-1}$. Density functional calculation reveals the migration of $\mathrm{Li}^{+}$through the heterojunction to $\mathrm{K}$ vacant sites in $\mathrm{K}_{2} \mathrm{CO}_{3}$ (201) with energy barrier of $0.58 \mathrm{eV}$. These results benefit the design of cathode architecture by two-staged discharge to construct heterostructure for long-life $\mathrm{Li}-\mathrm{O}_{2}$ batteries.

\section{Results}

Synthesis of binder-free air catalysts. As illustrated in Fig. 1a, a composite of carbonaceous coatings onto layered double oxide (LDO) nanoflakes is prepared by thermal decomposition of polyvinyl pyrrolidone (PVP) as nitrogen and carbon source to deposit on $\mathrm{Ni}$ foam with pre-loaded $\mathrm{CoFe}$ layered double hydroxides (LDH) arrays, denoted as PVP-C@LDO. Constructing building blocks of two-dimensional carbon nanosheet and LDO with embedded nanocrystals is beneficial for the integration of good chemical reactivity of LDO and superior electrical conductivity of carbon nanosheet with enhanced catalytic activity. Scanning electron microscopic (SEM) image showed that CoFe $\mathrm{LDH}$ nanoflake arrays were grown vertically onto nickel foam with a flower-like morphology (Supplementary Fig. 1a). XRD pattern of as-obtained nanoflake arrays exhibits a double relationship between the basal and second-order diffractions (Fig. 1b), characteristic for the $\mathrm{LDH}$ structure. The layered spacing of $\mathrm{CoFe} \mathrm{LDH}$ arrays calculated based on the (003) peak at $11.5^{\circ}$ is $\sim 7.7 \AA$, consistent with the spacing measured by high resolution transmission electron microscopy (HRTEM) (Supplementary Fig. 1c). After chemical vapor deposition (CVD), the lamellar morphology of $\mathrm{LDH}$ could also be maintained in PVPC@LDO (Fig. 1b, c). CoFe LDH arrays on $\mathrm{Ni}$ foam without carbon were also calcined under the same conditions to fabricate CoFe LDO for comparison. Different from the smooth surface of CoFe LDO, the surface of PVP-C@LDO nanoflakes is decorated with plenty of particles in the average size of $\sim 100 \mathrm{~nm}$ and covered with carbon layers (Fig. 1d, e). XRD analysis reveals that PVP-C@LDO is composed of CoFe alloy, Co, and graphitic carbon (Fig. 1b). The existence of $\mathrm{Co}$ and $\mathrm{Fe}$ is further demonstrated by Co $2 \mathrm{p}$ and $\mathrm{Fe} 2 \mathrm{p}$ X-ray photoelectron spectroscopic (XPS) spectra of PVP-C@LDO (Supplementary Fig. 2). HRTEM observation reveals the (110) facet of CoFe alloy of these particles and (002) facet of multilayered partially graphitic carbon on the outside layer (Fig. 1f). The elemental mapping of these nanoparticles further demonstrates the formation of $\mathrm{CoFe}$ alloy (Fig. 1g and Supplementary Fig. 3).

Activity and durability of cathode catalysts. The electrochemical properties of PVP-C@LDO as bifunctional catalysts for oxygen electrodes were evaluated at a constant current density of $100 \mathrm{~mA}$ $\mathrm{g}^{-1}$ with a cut-off capacity of $1.3 \mathrm{mAh} \mathrm{cm}^{-2}$ (based on the total mass of catalysts). A distinct discharge plateau is observed in the potential range of $2.8-2.6 \mathrm{~V}$ upon cycling in the profiles of PVPC@LDO (Fig. 2a). PVP-C@LDO could deliver a specific discharge capacity of $4333 \mathrm{mAh} \mathrm{g}^{-1}$, which means that the $\mathrm{Li}-\mathrm{O}_{2}$ battery based on PVP-C@LDO cathode was operated reversibly for over $86 \mathrm{~h}$ per cycle. At a cut-off voltage of $2.25 \mathrm{~V}$, CoFe LDO could only deliver a specific discharge capacity of $1250 \mathrm{mAh} \mathrm{g}^{-1}$ (Fig. 2b). The discharge of CoFe LDO exhibits slope-like profiles with distinct kinetic overpotential behavior (Fig. 2b). The delayed voltage response existed extensively at the start of discharge profiles of many cathode catalysts in the successive cycles $^{32-34}$, which might be closely associated with the $\mathrm{Li}^{+} / \mathrm{e}$ diffusion in solid or quasi-solid discharge products ${ }^{35}$. The linear voltage variation could be observed in the deep discharge profiles of Ir-decorated reduced graphene oxides $(\mathrm{Ir} / \mathrm{GO})^{36}$, glassy carbon ${ }^{37}$, or branched carbon nanofibers ${ }^{38}$. Viswanathan et al. ${ }^{37}$ proposed a metal-insulator-metal charge transport model to explore the electron transfer through $\mathrm{Li}_{2} \mathrm{O}_{2}$ film on glassy carbon. The above linear voltage drop was ascribed to the ohmic polarization induced by the inhibition of charge transport when the surface of the catalyst was completely covered by $\mathrm{Li}_{2} \mathrm{O}_{2}$ discharge products with poor electron conductivity. Derivation of dynamic equations further revealed the relationship between linear voltage variation and the disproportionation of $\mathrm{LiO}_{2}^{*}$ on the catalyst surface ${ }^{35,39}$. The initial charge profiles of PVP-C@LDO and CoFe LDO exhibit typical three regions distinguished from distinct difference in slope (Fig. 2a, b). The first charge voltage plateau at low voltage $(\sim 3.3 \mathrm{~V}$ vs $\left.\mathrm{Li} / \mathrm{Li}^{+}\right)$is related to the oxidation of the superoxide-like phase on the surface of $\mathrm{Li}_{2} \mathrm{O}_{2}$ with the coexistence of two phase $e^{40,41}$. The following slope-like charge profile is associated with the solidsolution delithiation to form off-stoichiometric $\mathrm{Li}_{2-x} \mathrm{O}_{2}{ }^{42,43}$. The second charge voltage plateau at $3.7-4.2 \mathrm{~V}$ is associated with the oxidation of $\mathrm{Li}_{2} \mathrm{O}_{2}$ cores with the insulating property. Compared 

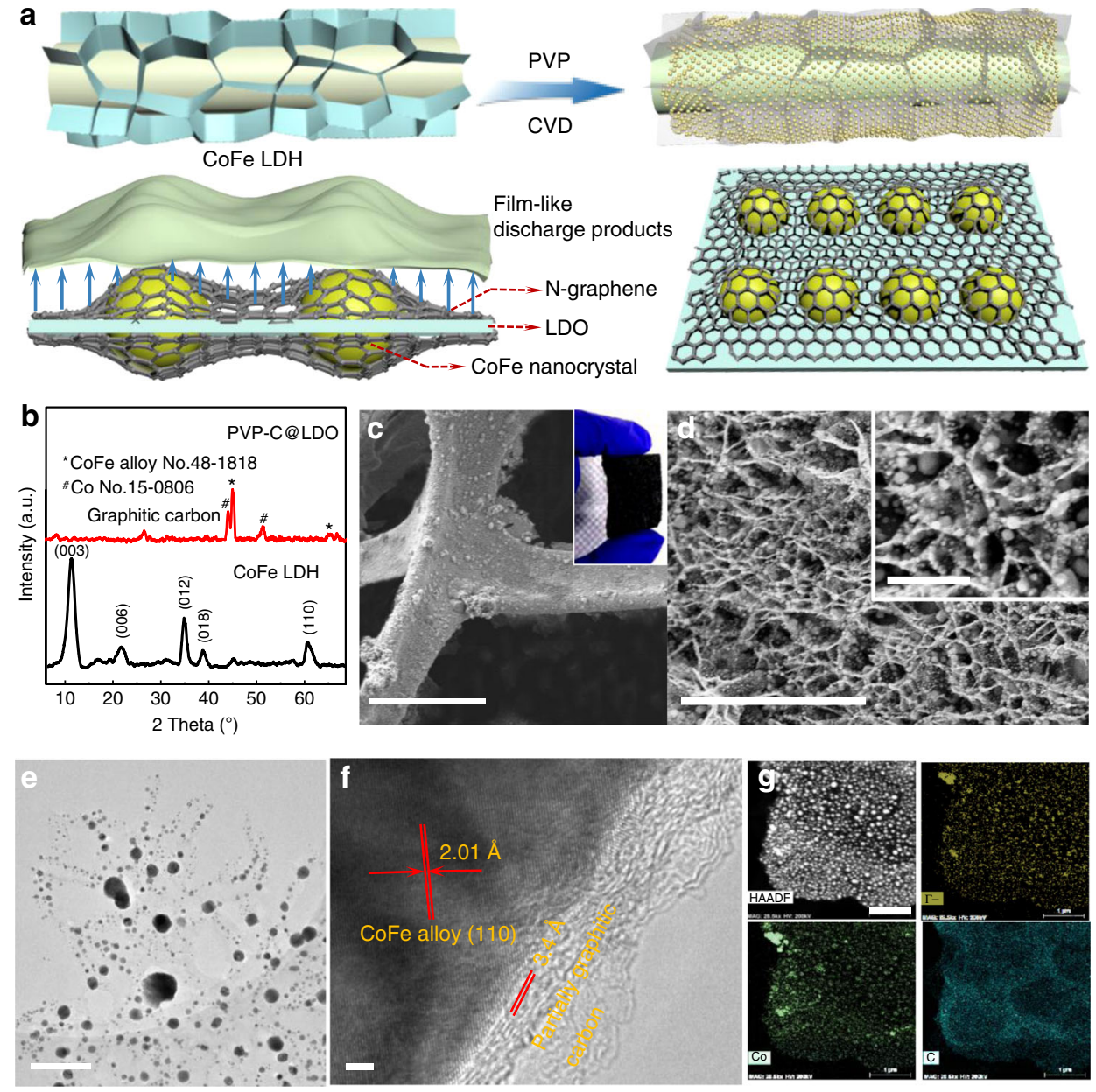

Fig. 1 Synthesis and analysis of the cathode catalysts. a Schemes for synthesis and the structure of PVP-C@LDO. b X-ray diffraction (XRD) patterns of CoFe LDH and PVP-C@LDO. c, d Scanning electron microscopic (SEM) image of PVP-C@LDO. Scale bars, 100 and $5 \mu \mathrm{m}$. Inset in d with scale bar of $1 \mu \mathrm{m}$. e, f Transmission electron microscopic (TEM) and high-resolution TEM (HRTEM) images of PVP-C@LDO. Scale bars, 500 and 2 nm. $\mathbf{g}$ Elemental mapping images of PVP-C@LDO. Scale bar, $1 \mu \mathrm{m}$.

with CoFe LDO with large capacity decay upon cycling (Fig. 2b), PVP-C@LDO exhibits enhanced cycling stability. However, the cycles of PVP-C@LDO are also limited, and fast-increasing charge overpotential is observed upon cycling. Co, Fe K-edge X-ray absorption fine structure (XAFS) spectra revealed the increase of valence states of Co and Fe in PVP-C@LDO after first charge (Supplementary Fig. 4), which might result in the change of electrochemical performance and the fast-increasing charge overpotential upon cycling. To address this issue for long-life $\mathrm{Li}-\mathrm{O}_{2}$ batteries, a two-step oxygen reduction approach is developed. At stage I, a discharged layer is deposited on the cathode surface in $\mathrm{K}^{-\mathrm{O}_{2}}$ battery as cathode surface protective layer. The successive discharge in $\mathrm{Li}-\mathrm{O}_{2}$ battery at stage II constructs heterostructure with band discontinuities and interfacial transition beneficial for the formation of defective discharge products. Figure $2 \mathrm{c}, \mathrm{d}$ shows the voltage profiles of PVP-C@LDO and CoFe LDO upon two-staged discharge in $\mathrm{K}-\mathrm{O}_{2}$ and $\mathrm{Li}-\mathrm{O}_{2}$ batteries. PVP-C@LDO could deliver a higher discharge capacity than CoFe LDO at stage I, while that is opposite at stage II. The weight of PVP-C@LDO electrodes after discharge at stage I is larger than that of initial electrodes. The cycles of PVP-C@LDO and CoFe LDO after two-staged discharge are fixed at a specific capacity of $1.3 \mathrm{mAh} \mathrm{cm}^{-2}$ in 2.25-4.2 V. Upon cycling, both PVP-C@LDO and CoFe LDO exhibit slope-like profiles without distinct charge voltage plateau. PVP-C@LDO can be operated reversibly over 70 cycles with a specific capacity of $\sim 3000 \mathrm{mAh} \mathrm{g}^{-1}$ (Fig. 2e), while CoFe LDO can be operated reversibly without distinct capacity decay up to 60 cycles (Fig. 2f). The cycling stabilities of PVPC@LDO and CoFe LDO are both greatly improved.

The deposition of discharge products on the cathode surface significantly affected the cathode/electrolyte interfacial resistance and the charge-transfer resistance on the cathode surface. Discharged PVP-C@LDO at stage II exhibits smaller cathode/ electrolyte interfacial and charge transport resistance than discharged cathode in conventional $\mathrm{Li}-\mathrm{O}_{2}$ batteries (Fig. 2g). The cathode/electrolyte interfacial resistance of discharged PVPC@LDO at stage II is less than half of that in conventional $\mathrm{Li}-\mathrm{O}_{2}$ batteries. Relative element fitting parameters in the equivalent circuit are detailed in Supplementary Table S1. Compared with pristine cathode operated in $\mathrm{O}_{2}$, the cyclic voltammetric $(\mathrm{CV})$ curve of PVP-C@LDO after discharge at stage I exhibits no distinct anodic peak (Fig. 2h), which is consistent with the disappearance of the first charge plateau in galvanostatic cycling profiles of PVP-C@LDO after stage II (Fig. 2e). The first charge voltage plateau is associated with the oxidation of $\mathrm{LiO}_{2}^{*}$ on the surface of $\mathrm{Li}_{2} \mathrm{O}_{2}{ }^{40,41}$. The introduction of the repository layer for $\mathrm{Li}^{+}$migration inducing the disappearance of the first charge plateau upon cycling indicates the feasible generation of offstoichiometric $\mathrm{Li}_{2-x} \mathrm{O}_{2}$ instead of intermediate $\mathrm{LiO}_{2}^{*}$ with distinct solid-solution behavior upon cycling (Fig. 2i). 

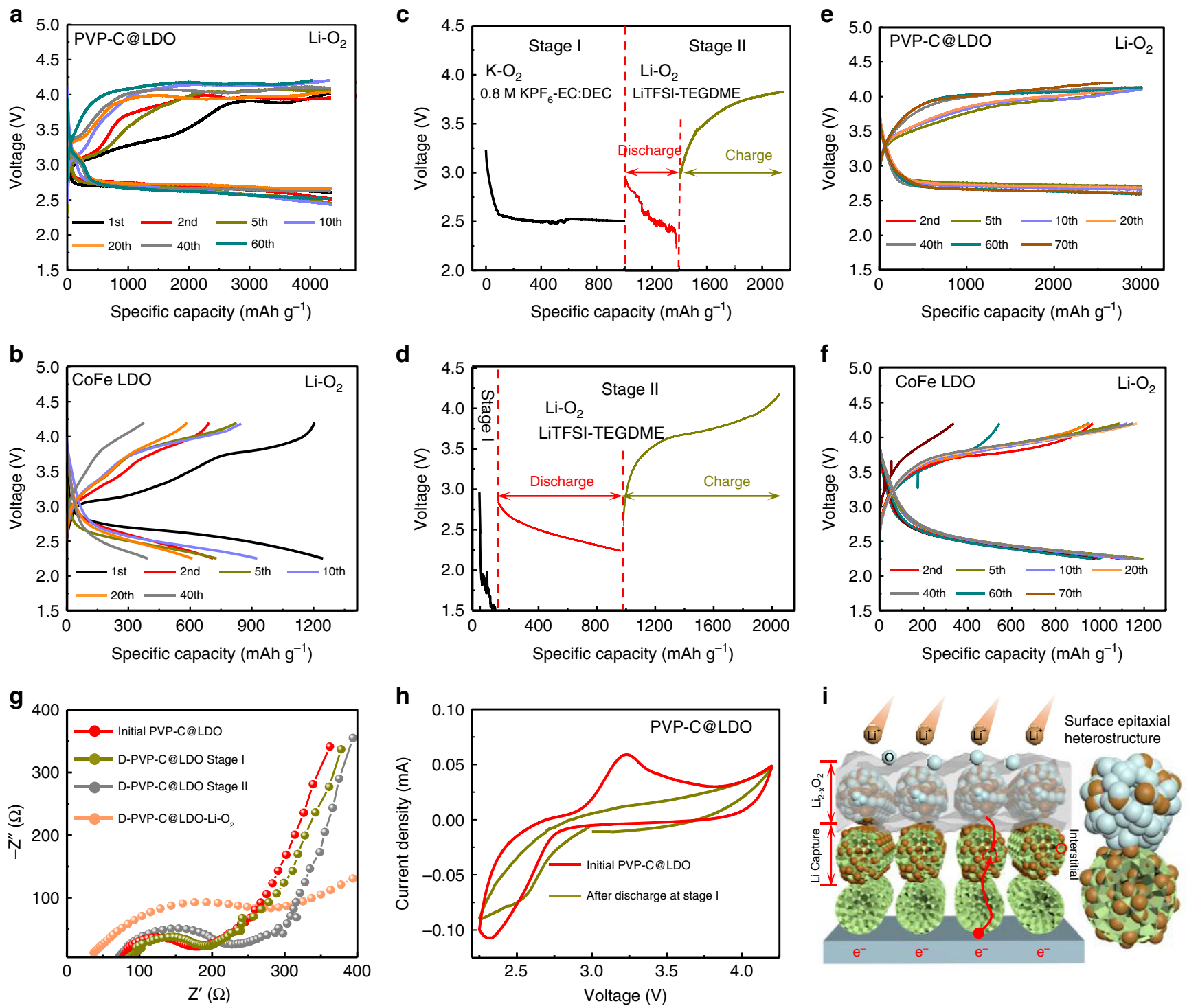

Fig. 2 Electrochemical performance. a, b PVP-C@LDO and CoFe LDO-based conventional Li-O $\mathrm{O}_{2}$ battery.c, d Multistaged pretreatment of PVP-C@LDO and CoFe LDO cathodes. Stage I: PVP-C@LDO/CoFe LDO|0.8 M KPF6-EC: DEC (1:1)|K. Stage II: PVP-C@LDO/CoFe LDO|1 M LiTFSI-TEGDME|Li. e, f Cycling performance of PVP-C@LDO and CoFe LDO after multistaged discharge. Current densities are $100 \mathrm{~mA} \mathrm{~g}^{-1}$. $\mathbf{g}$, h Nyquist plots and cyclic voltammetric (CV) curves of PVP-C@LDO before and after discharge at a stage I and stage II. i Schematic representation of the formation of film-like Li 2 ${ }_{-x} \mathrm{O}_{2}$ after multistaged discharge.

Multistaged discharge products. To explore the effect of the deposition of multilayers on the performance of $\mathrm{Li}-\mathrm{O}_{2}$ batteries, the properties of discharge products at different stages were further characterized. C $1 \mathrm{~s}$ XPS spectrum of initial PVP-C@LDO exhibits a characteristic $\pi-\pi^{*}$ transition satellite with extended delocalized electrons at $292.7 \mathrm{eV}$ (Supplementary Fig. 5). After discharge at stage I, characteristic K 2p XPS peaks with spin-orbit splitting of $2.8 \mathrm{eV}$ appeared, indicating the formation of discharge products on the catalyst surface containing K. N $1 \mathrm{~s}$ and O $1 \mathrm{~s}$ XPS spectra of PVP-C@LDO after discharge at stage I show enhanced shoulder peaks of pyridinic $\mathrm{N}$ and $\mathrm{Co} / \mathrm{Fe}-\mathrm{O}$ (Fig. 3a, b). The relative content of $\mathrm{CO}_{3}^{2-}$ component increased after discharge at stage I and further increased at stage II. XRD showed the deposition of hexagonal $\mathrm{K}_{2} \mathrm{CO}_{3}$ (JCPDS No. 27-1348) on discharged PVP-C@LDO at stage I with (201) preferential orientation (Fig. 3c). Distinct diffraction peaks of $\mathrm{K}_{2} \mathrm{CO}_{3}$ can also be found in the XRD patterns of discharged Super $\mathrm{P}$ cathodes over $8 \mathrm{~h}$ at stage I (Supplementary Fig. 6). No evidence of other potassium oxides, such as $\mathrm{K}_{2} \mathrm{O}_{2}, \mathrm{KO}_{2}$ or $\mathrm{K}_{2} \mathrm{O}$ could be detected. The existence of $\mathrm{CO}_{3}^{2-}$ and the absence of the $\mathrm{KO}_{2}$ and $\mathrm{K}_{2} \mathrm{O}_{2}$ were further revealed by Raman spectra of discharged PVP-C@LDO and Super P electrodes at stage I (Supplementary Fig. 7). Fourier transform infrared spectroscopy (FTIR) spectra of the discharged PVP-C@LDO at stage I and stage II further demonstrated the existence of $\mathrm{K}_{2} \mathrm{CO}_{3}$ (Fig. $3 \mathrm{~d}$ ). ${ }^{13} \mathrm{C}$ nuclear magnetic resonance (NMR) spectrum of Super P electrodes at stage I revealed the significant presence of $\mathrm{K}_{2} \mathrm{CO}_{3}(\delta=168.4$ ppm) (Supplementary Fig. 8). A relatively small amount of $\mathrm{CH}_{3} \mathrm{OK}(\delta=58.0 \mathrm{ppm})$ and $-\left(\mathrm{CH}_{2} \mathrm{CH}_{2} \mathrm{O}\right)_{n}-(\delta=69.7,67.6 \mathrm{ppm})$ could also be observed. These two species can be further identified in ${ }^{1} \mathrm{H}-\mathrm{NMR}$ spectrum $\left(\mathrm{CH}_{3} \mathrm{OK}, \delta=3.33 \mathrm{ppm} ;-\left(\mathrm{CH}_{2} \mathrm{CH}_{2} \mathrm{O}\right)_{n}-\right.$, $\delta=3.56,3.62 \mathrm{ppm})$. Based on the detected side products, the reaction mechanism related to the $\mathrm{K}_{2} \mathrm{CO}_{3}$ generation could be proposed based on the reductive cleavage of $\mathrm{C}-\mathrm{O}$ bonds of $\mathrm{EC}$ and DEC by solvated electrons (Supplementary Fig. 8c). The mass spectra of discharged Super P, PVP-C@LDO and CoFe LDO at stage II revealed the existence of $\mathrm{KLi}_{2} \mathrm{CO}_{3}^{+}, \mathrm{KLi}_{2} \mathrm{O}_{2}^{+}, \mathrm{K}_{2} \mathrm{Li}_{2} \mathrm{O}_{3}^{+}$ 

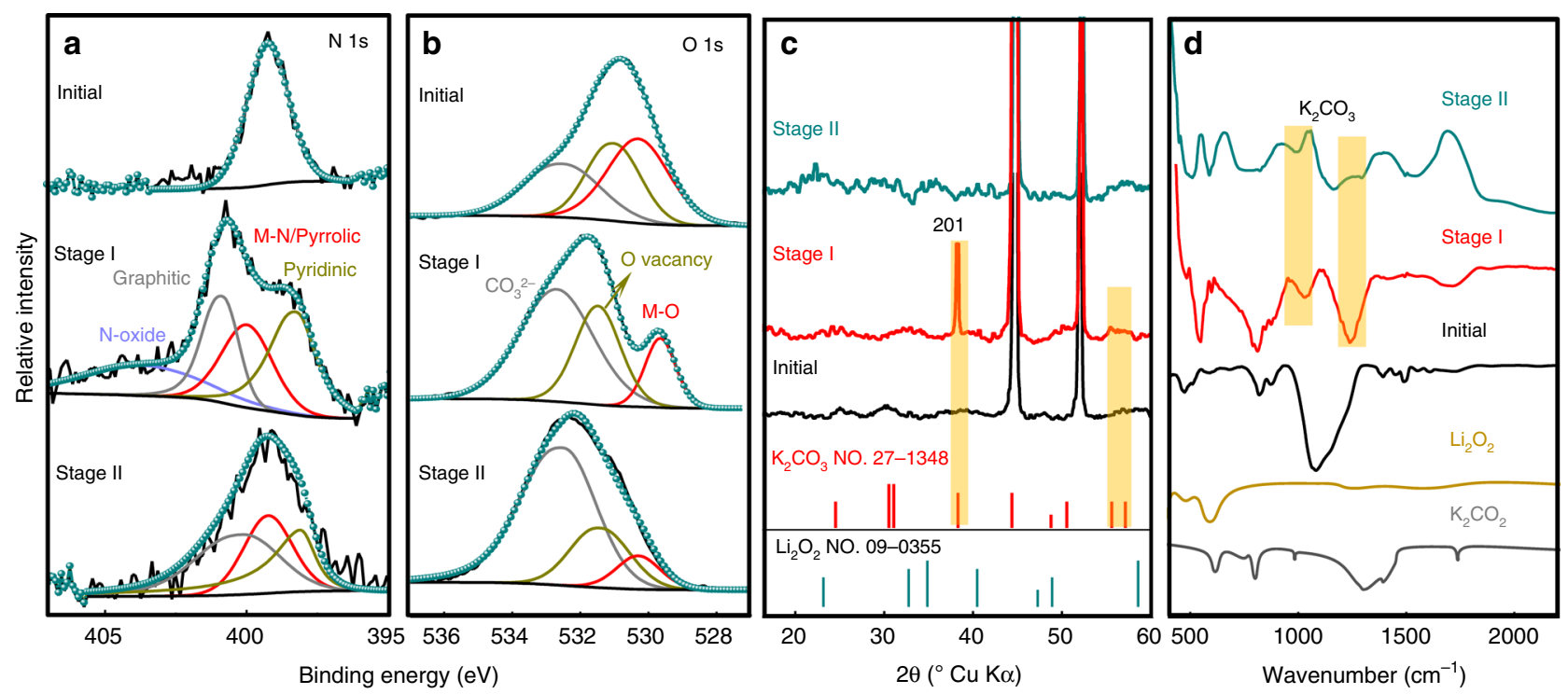

Fig. 3 Multistaged discharge products. a, b N 1s and O 1s X-ray photoelectron spectroscopy (XPS) spectra of initial PVP-C@LDO and discharged PVPC@LDO at stage I and stage II. c, d XRD patterns and Fourier transform infrared spectra of initial PVP-C@LDO and discharged PVP-C@LDO at stage I and stage II.

fragments, attributable to the construction $\mathrm{Li}_{2} \mathrm{O}_{2} / \mathrm{K}_{2} \mathrm{CO}_{3}$ heterostructure (Supplementary Fig. 9).

Morphologies of initial discharge products on the surface of PVP-C@LDO and CoFe LDO cathodes at different stages were further investigated by SEM and TEM observations. Large particles with a size of $\sim 200 \mathrm{~nm}$ are well dispersed on the surface of PVPC@LDO after discharge at Stage I (Fig. 4a-c). Distinct lattice fringes with spacings of approximately $2.3 \AA$ were detected for these cubic particles, attributable to the (201) facet of $\mathrm{K}_{2} \mathrm{CO}_{3}$ (Fig. 4c). SEM image of PVP-C@LDO after first discharge in traditional $\mathrm{Li}-\mathrm{O}_{2}$ battery showed typical toroid-shaped discharge products dispersed on the cathode surface (Fig. 4d). Further observation by HRTEM showed the distinct lattice fringes ascribable to $\mathrm{Li}_{2} \mathrm{O}_{2}$ (101) facet (Supplementary Fig. 10). However, the surface of discharged PVP-C@LDO in Li-O $\mathrm{O}_{2}$ battery at stage II was almost completely covered with a film-like coating (Fig. 4e). The existence of film-like discharge products could also be found in discharged CoFe LDO and Super P electrodes at stage II (Supplementary Figs. 11 and 12). Elemental mapping revealed the dispersion of $\mathrm{K}, \mathrm{C}$, and $\mathrm{O}$ in the outside layer of discharge products (Fig. 4f). Further observation of discharged PVP-C@LDO at stage II by HRTEM revealed the presence of heterojunction in discharge products (Fig. 4g). Distinct lattice spacings of 2.5 and $2.3 \AA$ could correspond to (101) facet of hexagonal $\mathrm{Li}_{2} \mathrm{O}_{2}$ and (201) facet of $\mathrm{K}_{2} \mathrm{CO}_{3}$, respectively. After charge at stage $\mathrm{II}, \mathrm{Li}_{2} \mathrm{O}_{2}$ grain crystal on the primary $\mathrm{K}_{2} \mathrm{CO}_{3}$ particles disappeared (Fig. $4 \mathrm{~h}$ ).

Heterostructure with enhanced charge transport. To explore the effect of heterostructure on the performance of $\mathrm{Li}-\mathrm{O}_{2}$ batteries, commercial $\mathrm{K}_{2} \mathrm{CO}_{3}$ was directly added into electrolyte or mixed with Super $\mathrm{P}$ to prepare the oxygen electrodes for comparison. When adding $\mathrm{K}_{2} \mathrm{CO}_{3}$ in electrolyte or coating $\mathrm{K}_{2} \mathrm{CO}_{3}$ with Super $\mathrm{P}$ on $\mathrm{Ni}$ foam, the capacity of Super $\mathrm{P}$ based $\mathrm{Li}-\mathrm{O}_{2}$ batteries was significantly reduced (Supplementary Fig. 13). Although Super P cathode after multistaged discharge delivered smaller reversible charge capacities than conventional Super P cathodes in $\mathrm{Li}-\mathrm{O}_{2}$ batteries, the durability of Super $\mathrm{P}$ cathode after multistaged discharge was also enhanced. To exclude the influence of fresh electrolyte on the cycling stability, the PVPC@LDO-based $\mathrm{Li}-\mathrm{O}_{2}$ battery was disassembled after first discharge, and a new battery was rebuilt with a new $\mathrm{Li}$ anode, separator, and fresh electrolyte. The first charge plateau of PVPC@LDO-based $\mathrm{Li}-\mathrm{O}_{2}$ batteries gradually faded away, and the cycles were very limited (Supplementary Fig. 14). These results demonstrated the critical role of $\mathrm{Li}_{2} \mathrm{O}_{2} / \mathrm{K}_{2} \mathrm{CO}_{3}$ heterostructure on the durability of $\mathrm{Li}-\mathrm{O}_{2}$ batteries.

Theoretically, a prerequisite for discharge products at stage I towards ideal $\mathrm{Li}_{2} \mathrm{O}_{2}$-based heterostructure is to have similar crystal structure with $\mathrm{Li}_{2} \mathrm{O}_{2}$ to avoid lattice mismatch. For discharge at stage I in $\mathrm{K}_{-} \mathrm{CO}_{2}$ battery with $0.8 \mathrm{M} \mathrm{KPF}_{6}$ in EC: DEC $(1: 1)$ as the electrolyte, $\mathrm{XRD}$ pattern revealed the deposition of monoclinic $\mathrm{K}_{2} \mathrm{CO}_{3}$ in $\mathrm{K}-\mathrm{CO}_{2}$ battery (Supplementary Fig. 15b). The cycle of Super P electrodes after multistaged discharge (stage I: $\mathrm{K}-\mathrm{CO}_{2}$ battery and stage II: $\mathrm{Li}-\mathrm{O}_{2}$ battery) is very limited with large irreversible charge capacities loss (Supplementary Fig. 15d). It is worse than that after two-staged discharge in $\mathrm{O}_{2}$. For two-staged discharge in $\mathrm{K}-\mathrm{O}_{2}$ and $\mathrm{Li}-\mathrm{O}_{2}$ batteries, the common superlattice of (101) facet of hexagonal $\mathrm{Li}_{2} \mathrm{O}_{2}$ and (201) facet of $\mathrm{K}_{2} \mathrm{CO}_{3}$ with a small mismatch in both lateral dimensions indicates a translational symmetry in favor of epitaxial growth over large distances. The heterostructure could be generated after two-staged discharge with continuous deposition of $\mathrm{K}_{2} \mathrm{CO}_{3}$ and $\mathrm{Li}_{2} \mathrm{O}_{2}$. The band gap of hexagonal $\mathrm{Li}_{2} \mathrm{O}_{2}$ and $\mathrm{K}_{2} \mathrm{CO}_{3}$ using general gradient approximation (GGA) functional with $U=6 \mathrm{eV}$ is 3.8 and $4.9 \mathrm{eV}$, respectively (Supplementary Fig. 16). The band gap could be drastically reduced after construction of the $\mathrm{K}_{2} \mathrm{CO}_{3} / \mathrm{Li}_{2} \mathrm{O}_{2}$ heterostructure. The Li migration through heterojunction was investigated by climbing-image nudged elastic band (CI-NEB) methods (Fig. 4i, j). The migration of $\mathrm{Li}$ through the $\mathrm{Li}_{2} \mathrm{O}_{2}$ (101) and $\mathrm{K}_{2} \mathrm{CO}_{3}$ (201) heterojunction to the $\mathrm{K}$ vacant sites in $\mathrm{K}_{2} \mathrm{CO}_{3}(201)$ is necessary to span across a transition state with an energy barrier of $0.58 \mathrm{eV}$.

Ex situ XRD analyses of Super P on carbon fiber paper (CFP) at different discharge states were utilized to evaluate the stoichiometry variation in discharge products after multistaged discharge at stage II by measuring the lattice constant change (Fig. 5a). Upon discharge at stage II, the intensity of the characteristic $\mathrm{Li}_{2} \mathrm{O}_{2}$ (100) peak increases gradually. The observed broad width and slight shift of the $\mathrm{Li}_{2} \mathrm{O}_{2}$ (100) peak before $12 \mathrm{~h}$ might indicate the less ordering of deposited $\mathrm{Li}_{2} \mathrm{O}_{2}$ discharge products. Compared with the discharged Super $\mathrm{P}$ electrode at $10 \mathrm{~h}$ in traditional $\mathrm{Li}-\mathrm{O}_{2}$ battery, an obvious shift of $\mathrm{Li}_{2} \mathrm{O}_{2}(100)$ peak to lower angle can be observed for discharged Super 



Fig. 4 Heterostructure. a-c SEM and TEM images of discharged PVP-C@LDO at stage I. Scale bars of a-c are $100 \mu \mathrm{m}, 2 \mu \mathrm{m}$ and $100 \mathrm{~nm}$, respectively. Scale bars of insets in b, c are $500 \mathrm{~nm}$ and $2 \mathrm{~nm}$, respectively. d SEM image of discharged PVP-C@LDO in conventional Li-O $\mathrm{O}_{2}$ battery. Scale bar, $5 \mu \mathrm{m}$. Scale bar of inset in $\mathbf{d}$ is $500 \mathrm{~nm}$. e-g SEM, elemental mapping and HRTEM images of discharged PVP-C@LDO at stage II. h HRTEM image of charged PVPC@LDO at stage II. Scale bars of $\mathbf{e}, \mathbf{f}, \mathbf{g}$, and $\mathbf{h}$ are $5 \mu \mathrm{m}, 50 \mathrm{~nm}, 2 \mathrm{~nm}$, and $2 \mathrm{~nm}$, respectively. Inset in $\mathbf{g}$ is the corresponding fast Fourier transformed image with scale bar of $5 \mathrm{~nm}^{-1}$ (green: $\mathrm{Li}_{2} \mathrm{O}_{2}$; yellow: $\mathrm{K}_{2} \mathrm{CO}_{3}$ ). $\mathbf{i}$ Energy barrier profile of $\mathrm{Li}^{+}$migration through heterojunction of $\mathrm{Li}_{2} \mathrm{O}_{2}(101) / \mathrm{K}_{2} \mathrm{CO}_{3}(201)$. The migration of $\mathrm{Li}^{+}$is marked as black dotted circle. $\mathbf{j} \mathrm{Li}^{+}$migration pathways into $\mathrm{K}$ vacant site of $\mathrm{K}_{2} \mathrm{CO}_{3}(201)$.

$\mathrm{P}$ electrode at $10 \mathrm{~h}$ at stage II, indicating the formation of offstoichiometric $\mathrm{Li}_{2-x} \mathrm{O}_{2}$ with larger lattice constants. It is consistent with the XRD analyses of off-stoichiometric perovskite films ${ }^{44,45}$ and the intercalated compounds upon deinsertion of metal ions ${ }^{46-48}$ with lattice expansion. To avoid the effect of unpaired spin from metal ions, Super P on CFP is utilized for electron paramagnetic resonance (EPR) measurements to study the defect in $\mathrm{Li}_{2} \mathrm{O}_{2}$ discharge products after multistaged discharge. The EPR spectra of discharged Super P at different time at stage II consist of a single quasi-symmetric resonance line
(Fig. 5b). The commercial $\mathrm{Li}_{2} \mathrm{O}_{2}$ powder is EPR silent. The $g$ factor of discharged Super $\mathrm{P}$ in conventional $\mathrm{Li}-\mathrm{O}_{2}$ battery is 2.006 corresponding to the characteristic signal of $\mathrm{LiO}_{2}^{* 49-51}$. However, the $g$ factor of discharged Super P at stage II is around 2.000. The variation of $g$ factor reflects the difference of orbital contributions, spin multiplicity or spin-spin coupling ${ }^{50}$ between EPR-active $\mathrm{LiO}_{2}^{*}$ in conventional $\mathrm{Li}-\mathrm{O}_{2}$ battery and the twostaged discharge products after pretreatment in $\mathrm{K}-\mathrm{O}_{2}$ battery. The EPR signal intensities of discharge Super $\mathrm{P}$ at stage II decrease with the discharge time (Fig. 5c). The strong intensity at 

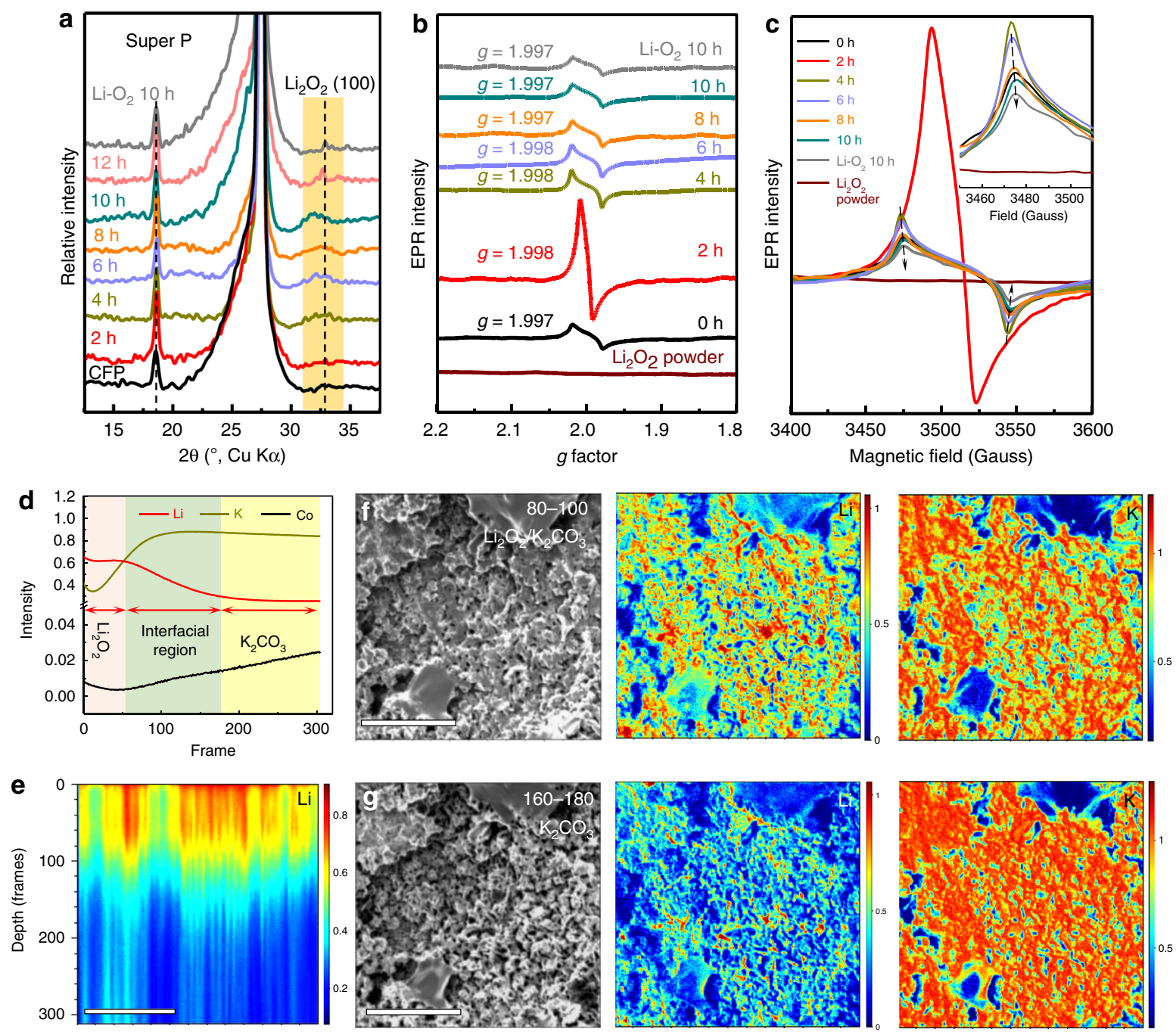

Fig. 5 Defects in $\mathbf{L i}_{\mathbf{2}} \mathbf{O}_{\mathbf{2}}$. a-c XRD patterns and electron paramagnetic resonance (EPR) spectra of conventional discharge and two-staged discharge of Super P. d Time-of-flight secondary ion mass spectrometric (TOF-SIMS) depth profile of discharged PVP-C@LDO at stage II. e The z-distribution map of $\mathrm{Li}^{+}$on discharged PVP-C@LDO cathode at stage II. f, g TOF-SIMS mapping in the depth of 80-100 frames ( 88-110 nm) and 160-180 frames

$(\sim 176-200 \mathrm{~nm})$. Scale bars of $\mathbf{e}-\mathbf{g}, 10 \mu \mathrm{m}$.

$2 \mathrm{~h}$ at stage II might be associated with the built-in field-induced charge transfer. The intensity of discharged Super $\mathrm{P}$ at $10 \mathrm{~h}$ at stage II is stronger than that of discharged Super $\mathrm{P}$ at $10 \mathrm{~h}$ in conventional $\mathrm{Li}-\mathrm{O}_{2}$ battery, indicative of more unpaired electrons in discharge products after multistaged discharge.

The chemical composition and distribution of $\mathrm{K}$ and $\mathrm{Li}$ throughout the discharged PVP-C@LDO at stage II is further investigated using time-of-flight secondary ion mass spectrometry (TOF-SIMS) in positive mode. The depth profile established by etching a selected area on the electrode surface under continuous $\mathrm{Ga}^{+}$sputtering can be divided into several regions (Fig. $5 \mathrm{~d}$ ). In the first $\sim 55$ frames $(\sim 60 \mathrm{~nm})$ of etching, the intensity plateau of $\mathrm{Li}^{+}$marks the $\mathrm{Li}_{2} \mathrm{O}_{2}$ region with a relatively homogenous indepth composition. After $\sim 55$ frames, the intensity of $\mathrm{Li}^{+}$starts to decrease while that of $\mathrm{K}^{+}$increases gradually to the maximum. This marks the beginning of the $\mathrm{Li}_{2} \mathrm{O}_{2} / \mathrm{K}_{2} \mathrm{CO}_{3}$ interfacial region. Such variation is observed until $\sim 150$ frames, at which the $\mathrm{Li}$ and $\mathrm{K}$ signals are stable, thus marking the end of this interfacial region. The $\mathrm{z}$-distribution mapping image of $\mathrm{Li}^{+}$on discharged PVP-C@LDO cathode at stage II reveals that species containing $\mathrm{Li}$ has penetrated into the surface with depth of $\sim 150 \mathrm{~nm}$ (Fig. 5e). The focused ion-beam SEM (FIB-SEM) mapping images reveal that film-like discharge products on the surface of discharged PVP-C@LDO cathode at stage II contain $\mathrm{K}$ and Li with clear contrast variations (Fig. $5 f$, g). The superposition of $\mathrm{Li}$ and $\mathrm{K}$ in the interfacial region might suggest the favorable deposition of $\mathrm{Li}_{2} \mathrm{O}_{2}$ on the substrate $\mathrm{K}_{2} \mathrm{CO}_{3}$ layer.

\section{Discussion}

Constructing $\mathrm{Li}_{2} \mathrm{O}_{2}$-based heterostructure with band discontinuities and interfacial transition offers a promising strategy to enhance charge transport in discharge products for long-life $\mathrm{Li}-\mathrm{O}_{2}$ batteries. A two-step oxygen reduction approach is developed to construct $\mathrm{K}_{2} \mathrm{CO}_{3} / \mathrm{Li}_{2} \mathrm{O}_{2}$ heterostructure by predepositing a layer of $\mathrm{K}_{2} \mathrm{CO}_{3}$ on cathode surface in $\mathrm{K}-\mathrm{O}_{2}$ battery and epitaxial growth of $\mathrm{Li}_{2} \mathrm{O}_{2}$ after successive discharge in $\mathrm{Li}-\mathrm{O}_{2}$ battery. The built-in field of the heterostructure could contribute to the formation of defects at surface/interface for enhanced charge transport in discharge products.

Typically, the cycles of Super $\mathrm{P}$ cathodes operated in $\mathrm{O}_{2}$ were very limited, less than 20 cycles at a fixed capacity of $0.6 \mathrm{mAh} \mathrm{cm}^{-2}$. The poor durability with sluggish and unsustainable electrochemical reactions on Super P cathode is mainly originated from the insufficient charge transfer and the limited contact area between toroidal 
$\mathrm{Li}_{2} \mathrm{O}_{2}$ and catalysts ${ }^{4,8,52-54}$. After multistaged discharge, Super P cathode operated in $\mathrm{O}_{2}$ exhibited significantly enhanced cycling stability in spite of severe irreversible charge capacity loss (Supplementary Fig. 13). This severe irreversible charge capacity loss induced by large overpotential could be alleviated by exploiting cathode catalysts, such as PVP-C@LDO in this work with enhanced catalytic effect towards the decomposition of discharge products.

After constructing heterostructure by the two-staged discharge, both PVP-C@LDO and CoFe LDO-based Li- $\mathrm{O}_{2}$ batteries exhibited distinct solid-solution behavior without distinct charge voltage plateau upon cycling. The cycling stability of PVPC@LDO and CoFe LDO were both greatly improved (Fig. 2e, f). PVP-C@LDO-based $\mathrm{Li}-\mathrm{O}_{2}$ batteries could be operated reversibly over 70 cycles without capacity decay at a limited specific capacity of $3000 \mathrm{mAh} \mathrm{g}^{-1}$. The main discharge product of $\mathrm{K}_{2} \mathrm{CO}_{3}$ at stage I in EC: DEC electrolyte was characterized by XPS, ${ }^{13} \mathrm{C}-\mathrm{NMR}$, Raman, FTIR and mass spectra. The presence of heterostructure after two-staged discharge is revealed by HRTEM and TOF-SIMS characterization. SEM observation revealed the formation of filmlike discharge products on the surface of discharged PVP$\mathrm{C} @ \mathrm{LDO}$ at stage II (Fig. 4e). Compared with toroidal $\mathrm{Li}_{2} \mathrm{O}_{2}$, the film-like discharge products on the cathode surface with relatively large contact area can enable facile electron transport in favor of electrochemical decomposition of $\mathrm{Li}_{2} \mathrm{O}_{2}{ }^{10,55}$. The enhanced charge transport in $\mathrm{Li}_{2} \mathrm{O}_{2}$ after two-staged discharge by the construction of heterostructure is further revealed by electrochemical impedance, ex situ XRD and EPR spectroscopic analyses. $\mathrm{K}_{2} \mathrm{CO}_{3}$ additive had been reported to increase the cyclic performance of graphite by the formation of SEI films in Li-ion batteries ${ }^{56,57}$. To reveal the effect of the heterostructure on the properties of $\mathrm{Li}-\mathrm{O}_{2}$ batteries, commercial $\mathrm{K}_{2} \mathrm{CO}_{3}$ was directly added into the electrolyte or mixed with Super $\mathrm{P}$ to prepare the oxygen electrodes for comparison. When adding $\mathrm{K}_{2} \mathrm{CO}_{3}$ in electrolyte or coating $\mathrm{K}_{2} \mathrm{CO}_{3}$ on $\mathrm{Ni}$ foam, the capacities of Super $\mathrm{P}$ based $\mathrm{Li}-\mathrm{O}_{2}$ batteries were significantly reduced (Supplementary Fig. 13). These results revealed the critical role of heterostructure on the durability of $\mathrm{Li}-\mathrm{O}_{2}$ batteries.

In summary, constructing heterostructure through a twostaged discharge has been shown to improve the cycling stability of $\mathrm{Li}-\mathrm{O}_{2}$ batteries. The improvement of cycling stability might be closely associated with the enhanced charge transport in discharge products and the formation of film-like instead of large toroidal discharge products to alleviate passivation/clogging of the cathode. This new strategy opens promising avenues for the development of long-life $\mathrm{Li}-\mathrm{O}_{2}$ batteries through constructing heterostructure after multistaged discharge.

\section{Methods \\ Cathode preparation. $0.74 \mathrm{~mL}$ of concentrated ammonia $(28 \mathrm{wt} \%)$ was added dropwise into to $40 \mathrm{~mL} 5 \mathrm{mmol} \mathrm{Co}\left(\mathrm{NO}_{3}\right)_{2}$ and $2.5 \mathrm{mmol} \mathrm{Fe}\left(\mathrm{NO}_{3}\right)_{2}$ aqueous solution to form a homogeneous solution under vigorous stirring. At a constant potential of $-2.0 \mathrm{~V}$ (vs SCE), CoFe LDH was electrodeposited onto the nickel foam for $600 \mathrm{~s}$ in the above electrolyte with platinum foil as the counter electrode. The generated $\mathrm{CoFe} \mathrm{LDH}$ on the nickel foam was rinsed twice with deionized water and then anhydrous ethanol, dried at $60^{\circ} \mathrm{C}$ for $6 \mathrm{~h}$. PVP-C@LDO is prepared by CVD. Typically, a quartz boat with $0.8 \mathrm{~g}$ PVP was placed in the upstream zone of the quartz tube. Five pieces of $\mathrm{CoFe} \mathrm{LDH}$ arrays on Ni foam disks with a diameter of $12 \mathrm{~mm}$ were placed in the downstream zone of the tube, which was $10 \mathrm{~cm}$ away from the quart tube in the upstream zone. Ar was introduced to the system with a flowing rate of $150 \mathrm{~mL} \mathrm{~min}-1$. The furnace was heated to $550{ }^{\circ} \mathrm{C}$ with heating ramps of $5^{\circ} \mathrm{C} \mathrm{min}-1$. After $10 \mathrm{~min}$, the furnace was heated to $900^{\circ} \mathrm{C}$ and held for 30 min before being allowed to cool down naturally. For comparison, CoFe LDO is prepared by calcinating CoFe LDO arrays without adding PVP as carbon and nitrogen sources under the same condition.}

Electrochemistry. The electrochemical performance was analyzed using a CR2025type Swagelok coin battery. All of the batteries were assembled in a glove box filled with ultra-highly pure Ar using Millipore glass fiber film as the separator. Discharge at stage $\mathrm{I}$ was in a $\mathrm{K}-\mathrm{O}_{2}$ battery with $\mathrm{K}$ metal foil as anodes and $0.8 \mathrm{M} \mathrm{KPF}_{6}$ in $\mathrm{EC}$ :
DEC (1: 1) as electrolyte. The discharged cathode at stage I was disassembled, washed with DEC and dried in $\mathrm{CO}_{2}$ overnight. A new battery was rebuilt with the discharged cathode, Li anode and $1 \mathrm{M}$ LiTFSI in the TEGDME electrolyte. For comparison, commercial $\mathrm{K}_{2} \mathrm{CO}_{3}$ powder mixing with Super P and PVDF (8: 1: 1) was coated on $\mathrm{Ni}$ foam to fabricate the cathodes for traditional $\mathrm{Li}-\mathrm{O}_{2}$ batteries. Super $\mathrm{P}$ cathodes were operated in $\mathrm{O}_{2}$ using $1 \mathrm{M} \mathrm{LiTFSI}+10 \mathrm{mM} \mathrm{K}_{2} \mathrm{CO}_{3}$ additive, and $1 \mathrm{M}$ LiTFSI in TEGDME. The $\mathrm{K}-\mathrm{CO}_{2}$ batteries were assembled with Super $\mathrm{P}$ electrodes as cathodes, $\mathrm{K}$ metal foil as anodes and $0.8 \mathrm{M} \mathrm{KPF}_{6}$ in EC: DEC (1:1) as electrolyte. The cathodes are dried at $80^{\circ} \mathrm{C}$ under vacuum for $10 \mathrm{~h}$.

Characterizations and measurements. XRD patterns were recorded on a $\mathrm{D} / \mathrm{max}$ $2550 \mathrm{VL} / \mathrm{PC} \mathrm{X}$-ray diffractometer (Rigaku, Japan) equipped with $\mathrm{Cu} \mathrm{K}_{\alpha}$ radiation $(\lambda=1.5418 \AA, 40 \mathrm{kV}, 30 \mathrm{~mA})$. FTIR was measured on a Spectrum 100 (PerkinElmer). XPS was performed on an AXIS Ultra DLD spectrometer (Kratos, Japan) with $\mathrm{Al} \mathrm{K}_{\alpha}$ radiation $(h v=1486.6 \mathrm{eV})$. Raman microprobe spectroscopy was performed on Thermo Fisher DXR, Waltham, MA, USA with an $\mathrm{Ar}^{+}$laser. The morphology of the samples was observed using a FESEM (FEI NOVA Nano SEM 230, USA). TEM and HRTEM observations were carried out on a JEM-2100F microscope operated at an acceleration voltage of $200 \mathrm{kV}$. TOF-SIMS and TOFSEM were carried out on a TESCAN Gaia3 FESEM. EPR measurements were carried out on a Bruker ELEXSYS E580 spectrometer $(9-10 \mathrm{GHz})$. The products in cathodes at stage I were extracted by $\mathrm{D}_{2} \mathrm{O}$ and tested by nuclear magnetic resonance (NMR) (Bruker, $400 \mathrm{MHz}$ ). The X-ray absorption (XAFS) data at the Co and Fe K-edge of the samples were recorded in transmission mode at room temperature using ion chambers (referenced samples) and fluorescence excitation mode using a Lytle detector (controlled samples) at beamline BL14W1 of the Shanghai Synchrotron Radiation Facility. During the measurement, the synchrotron was operated at $3.5 \mathrm{GeV}$ and the current was controlled between 150 and $210 \mathrm{~mA}$. Data processing was performed using the program ATHENA.

DFT calculations. First-principles electronic structure calculations were carried out using the Vienna ab initio simulation package (VASP) code $\mathrm{e}^{58,59}$ within the generalized gradient approximation (GGA) approach ${ }^{60}$. The generalized gradient approximation (GGA) with the Perdew-Burke-Ernzerhof (PBE) functional was used to describe the electronic exchange and correlation effects. Uniform Gcentered k-points meshes with a resolution of $2 \pi \times 0.04 \AA^{-1}$ and MethfesselPaxton electronic smearing were adopted for the integration in the Brillouin zone for geometric optimization. The simulation was run with a cut-off energy of $500 \mathrm{eV}$ throughout the computations. These settings ensure convergence of the total energies to within $1 \mathrm{meV}$ per atom. Structure relaxation proceeded until all forces on atoms were less than $1 \mathrm{meV}^{-1}$ and the total stress tensor was within $0.01 \mathrm{GPa}$ of the target value. The energy barriers of diffusion pathways were calculated by climbing-image nudged elastic band (CI-NEB) method ${ }^{61}$. Hubbard corrections to the DFT Hamiltonian was introduced on the $2 \mathrm{p}$ orbitals of carbon and oxygen atoms to describe properly the localization of polarons using general gradient approximation (GGA) functional with $\mathrm{U}=6 \mathrm{eV}^{28}$.

\section{Data availability}

The data that support the findings within this paper are available from the corresponding author on request.

Received: 5 August 2019; Accepted: 5 November 2019; Published online: 20 December 2019

\section{References}

1. Lim, H.-D. et al. Reaction chemistry in rechargeable $\mathrm{Li}-\mathrm{O}_{2}$ batteries. Chem. Soc. Rev. 46, 2873-2888 (2017).

2. Lyu, Z. et al. Recent advances in understanding of the mechanism and control of $\mathrm{Li}_{2} \mathrm{O}_{2}$ formation in aprotic $\mathrm{Li}^{-} \mathrm{O}_{2}$ batteries. Chem. Soc. Rev. 46, 6046-6072 (2017)

3. Wang, K. X., Zhu, Q. C. \& Chen, J. S. Strategies toward high-performance cathode materials for lithium-oxygen batteries. Small 14, 1800078 (2018).

4. Wang, J., Zhang, Y., Guo, L., Wang, E. \& Peng, Z. Identifying reactive sites and transport limitations of oxygen reactions in aprotic lithium- $\mathrm{O}_{2}$ batteries at the stage of sudden death. Angew. Chem. Int. Ed. 55, 5201-5205 (2016).

5. Lee, B. et al. Theoretical evidence for low charging overpotentials of superoxide discharge products in metal-oxygen batteries. Chem. Mater. 27, 8406-8413 (2015).

6. Dutta, A. et al. Nanostructuring one-dimensional and amorphous lithium peroxide for high round-trip efficiency in lithium-oxygen batteries. Nat. Commun. 9, 680 (2018)

7. Yao, X., Dong, Q., Cheng, Q. \& Wang, D. Why do lithium-oxygen batteries fail: Parasitic chemical reactions and their synergistic effect. Angew. Chem. Int Ed. 55, 11344-11353 (2016). 
8. Feng, N., He, P. \& Zhou, H. Critical challenges in rechargeable aprotic $\mathrm{Li}-\mathrm{O}_{2}$ batteries. Adv. Energy Mater. 6, 1502303 (2016).

9. Yang, C. et al. Unexpected $\mathrm{Li}_{2} \mathrm{O}_{2}$ film growth on carbon nanotube electrodes with $\mathrm{CeO}_{2}$ nanoparticles in $\mathrm{Li}_{-} \mathrm{O}_{2}$ batteries. Nano. Lett. 16, 2969-2974 (2016).

10. Yilmaz, E., Yogi, C., Yamanaka, K., Ohta, T. \& Byon, H. R. Promoting formation of noncrystalline $\mathrm{Li}_{2} \mathrm{O}_{2}$ in the $\mathrm{Li}-\mathrm{O}_{2}$ battery with $\mathrm{RuO}_{2}$ nanoparticles. Nano. Lett. 13, 4679-4684 (2013).

11. Kim, B.-G. et al. Improved reversibility in lithium-oxygen battery: understanding elementary reactions and surface charge engineering of metal alloy catalyst. Sci. Rep. 4, 4225 (2014).

12. Lim, H.-D. et al. A new catalyst-embedded hierarchical air electrode for highperformance $\mathrm{Li}_{-} \mathrm{O}_{2}$ batteries. Energy Environ. Sci. 6, 3570-3575 (2013).

13. Radin, M. D., Monroe, C. W. \& Siegel, D. J. How dopants can enhance charge transport in $\mathrm{Li}_{2} \mathrm{O}_{2}$. Chem. Mater. 27, 839-847 (2015).

14. Okuoka, S.-I. et al. A new sealed lithium-peroxide battery with a Co-doped $\mathrm{Li}_{2} \mathrm{O}$ cathode in a superconcentrated lithium bis(fluorosulfonyl) amide electrolyte. Sci. Rep. 4, 5684 (2014).

15. Lyu, Z. et al. Promoting defective- $\mathrm{Li}_{2} \mathrm{O}_{2}$ formation via $\mathrm{Na}$ doping for $\mathrm{Li}-\mathrm{O}_{2}$ batteries with low charge overpotentials. J. Mater. Chem. A. https://doi.org/ 10.1039/C9TA01606F (2019).

16. Varley, J., Viswanathan, V., Nørskov, J. \& Luntz, A. Lithium and oxygen vacancies and their role in $\mathrm{Li}_{2} \mathrm{O}_{2}$ charge transport in $\mathrm{Li}-\mathrm{O}_{2}$ batteries. Energy Environ. Sci. 7, 720-727 (2014).

17. Yang, G., Wang, Y. \& Ma, Y. A stable, magnetic, and metallic $\mathrm{Li}_{3} \mathrm{O}_{4}$ compound as a discharge product in a Li-air battery. J. Phys. Chem. Lett. 5, 2516-2521 (2014).

18. Zhang, P., Zhao, Y. \& Zhang, X. Functional and stability orientation synthesis of materials and structures in aprotic Li- $\mathrm{O}_{2}$ batteries. Chem. Soc. Rev. 47, 2921-3004 (2018).

19. Lu, Y.-C. et al. The discharge rate capability of rechargeable $\mathrm{Li}^{-} \mathrm{O}_{2}$ batteries. Energy Environ. Sci. 4, 2999-3007 (2011).

20. Aurbach, D., McCloskey, B. D., Nazar, L. F. \& Bruce, P. G. Advances in understanding mechanisms underpinning lithium-air batteries. Nat. Energy 1, 16128 (2016)

21. Ganapathy, $\mathrm{S}$. et al. Nature of $\mathrm{Li}_{2} \mathrm{O}_{2}$ oxidation in a $\mathrm{Li}-\mathrm{O}_{2}$ battery revealed by operando X-ray diffraction. J. Am. Chem. Soc. 136, 16335-16344 (2014).

22. Ganapathy, S. et al. Operando nanobeam diffraction to follow the decomposition of individual $\mathrm{Li}_{2} \mathrm{O}_{2}$ grains in a nonaqueous $\mathrm{Li}-\mathrm{O}_{2}$ battery. $J$. Phys. Chem. Lett. 7, 3388-3394 (2016).

23. $\mathrm{Li}, \mathrm{Z}$. et al. Understanding the electrochemical formation and decomposition of $\mathrm{Li}_{2} \mathrm{O}_{2}$ and $\mathrm{LiOH}$ with operando X-ray diffraction. Chem. Mater. 29, 1577-1586 (2017).

24. Shi, S., Qi, Y., Li, H. \& Hector, L. G. Defect thermodynamics and diffusion mechanisms in $\mathrm{Li}_{2} \mathrm{CO}_{3}$ and implications for the solid electrolyte interphase in Li-ion batteries. J. Phys. Chem. C. 117, 8579-8593 (2013).

25. Zhang, Q. et al. Synergetic effects of inorganic components in solid electrolyte interphase on high cycle efficiency of lithium ion batteries. Nano. Lett. 16, 2011-2016 (2016).

26. Yang, Y. et al. Highly stable cycling of amorphous $\mathrm{Li}_{2} \mathrm{CO}_{3}$-coated $\alpha-\mathrm{Fe}_{2} \mathrm{O}_{3}$ nanocrystallines prepared via a new mechanochemical strategy for Li-ion batteries. Adv. Funct. Mater. 27, 1605011 (2017).

27. McCloskey, B. et al. Twin problems of interfacial carbonate formation in nonaqueous $\mathrm{Li}-\mathrm{O}_{2}$ batteries. J. Phys. Chem. Lett. 3, 997-1001 (2012).

28. Garcia-Lastra, J. M., Myrdal, J. S., Christensen, R., Thygesen, K. S. \& Vegge, T. $\mathrm{DFT}+\mathrm{U}$ study of polaronic conduction in $\mathrm{Li}_{2} \mathrm{O}_{2}$ and $\mathrm{Li}_{2} \mathrm{CO}_{3}$ : Implications for Li-air batteries. J. Phys. Chem. C. 117, 5568-5577 (2013).

29. Capasso, F. \& Margaritondo, G. Heterojunction Band Discontinuities: Physics and Device Applications (North-Holland, 1987).

30. Tan, C., Chen, J., Wu, X.-J. \& Zhang, H. Epitaxial growth of hybrid nanostructures. Nat. Rev. Mater. 3, 17089 (2018)

31. Yu, L. \& Zunger, A. A polarity-induced defect mechanism for conductivity and magnetism at polar-nonpolar oxide interfaces. Nat. Commun. 5, 5118 (2014).

32. Sun, B., Huang, X., Chen, S., Munroe, P. \& Wang, G. Porous graphene nanoarchitectures: an efficient catalyst for low charge-overpotential, long life, and high capacity lithium-oxygen batteries. Nano. Lett. 14, 3145-3152 (2014).

33. $\mathrm{Xu}, \mathrm{S}$. M. et al. Low-overpotential $\mathrm{Li}_{-} \mathrm{O}_{2}$ batteries based on TFSI intercalated Co-Ti layered double oxides. Adv. Funct. Mater. 26, 1365-1374 (2016).

34. Johnson, $\mathrm{L}$. et al. The role of $\mathrm{LiO}_{2}$ solubility in $\mathrm{O}_{2}$ reduction in aprotic solvents and its consequences for $\mathrm{Li}_{-} \mathrm{O}_{2}$ batteries. Nat. Chem. 6, 1091 (2014).

35. Xu, S. M., Liang, X., Ren, Z. C., Wang, K. X. \& Chen, J. S. Free-standing air cathodes based on 3D hierarchically porous carbon films: Kinetic overpotential of continuous macropores in $\mathrm{Li}_{-} \mathrm{O}_{2}$ batteries. Angew. Chem. Int. Ed. 130, 6941-6945 (2018).

36. Lu, J. et al. A lithium-oxygen battery based on lithium superoxide. Nature 529, 377 (2016).

37. Viswanathan, V. et al. Electrical conductivity in $\mathrm{Li}_{2} \mathrm{O}_{2}$ and its role in determining capacity limitations in non-aqueous $\mathrm{Li}^{-} \mathrm{O}_{2}$ batteries. J. Chem. Phys. 135, 214704 (2013).
38. Lim, H.-D. et al. Three-dimensionally branched carbon nanowebs as aircathode for redox-mediated $\mathrm{Li}^{-\mathrm{O}_{2}}$ batteries. Carbon N. Y. 118, 114-119 (2017).

39. Viswanathan, V. et al. Li- $\mathrm{O}_{2}$ kinetic overpotentials: Tafel plots from experiment and first-principles theory. J. Phys. Chem. Lett. 4, 556-560 (2013)

40. Yang, J. et al. Evidence for lithium superoxide-like species in the discharge product of a Li- $\mathrm{O}_{2}$ battery. Phys. Chem. Chem. Phys. 15, 3764-3771 (2013).

41. $\mathrm{Xu}, \mathrm{S}$. M. et al. Toward lower overpotential through improved electron transport property: Hierarchically porous $\mathrm{CoN}$ nanorods prepared by nitridation for lithium-oxygen batteries. Nano. Lett. 16, 5902-5908 (2016)

42. Gallant, B. M. et al. Influence of $\mathrm{Li}_{2} \mathrm{O}_{2}$ morphology on oxygen reduction and evolution kinetics in $\mathrm{Li}_{-} \mathrm{O}_{2}$ batteries. Energy Environ. Sci. 6, 2518-2528 (2013).

43. Mitchell, R. R., Gallant, B. M., Shao-Horn, Y. \& Thompson, C. V. Mechanisms of morphological evolution of $\mathrm{Li}_{2} \mathrm{O}_{2}$ particles during electrochemical growth. J. Phys. Chem. Lett. 4, 1060-1064 (2013).

44. Lee, H. N., Seo, S. A., Choi, W. S. \& Rouleau, C. M. Growth control of oxygen stoichiometry in homoepitaxial $\mathrm{SrTiO}_{3}$ films by pulsed laser epitaxy in high vacuum. Sci. Rep. 6, 19941 (2016).

45. $\mathrm{Xu}, \mathrm{C}$. et al. Impact of the interplay between nonstoichiometry and kinetic energy of the plume species on the growth mode of $\mathrm{SrTiO}_{3}$ thin films. J. Phys. D: Appl. Phys. 47, 034009 (2013).

46. $\mathrm{Xu}, \mathrm{S}$. M. et al. Boosting potassium storage capacity based on stress-induced size-dependent solid-solution behavior. Adv. Energy Mater. 8, 1802175 (2018).

47. Kim, $\mathrm{H}$. et al. $\mathrm{K}$-ion batteries based on a $\mathrm{P} 2$-type $\mathrm{K}_{0.6} \mathrm{CoO}_{2}$ cathode. $A d v$. Energy Mater. 7, 1700098 (2017).

48. Lu, Z. et al. Electrochemical tuning of layered lithium transition metal oxides for improvement of oxygen evolution reaction. Nat. Commun. 5, 4345 (2014)

49. Ou, G. et al. Tuning defects in oxides at room temperature by lithium reduction. Nat. Commun. 9, 1302 (2018).

50. Lindsay, D. \& Garland, D. ESR spectra of matrix-isolated lithium superoxide. J. Phys. Chem. 91, 6158-6161 (1987).

51. Lin, $\mathrm{X}$. et al. Controlling reversible expansion of $\mathrm{Li}_{2} \mathrm{O}_{2}$ formation and decomposition by modifying electrolyte in $\mathrm{Li}_{-} \mathrm{O}_{2}$ batteries. Chem 4, 2685-2698 (2018).

52. Song, $\mathrm{S}$. et al. Complete decomposition of $\mathrm{Li}_{2} \mathrm{CO}_{3}$ in $\mathrm{Li}-\mathrm{O}_{2}$ batteries using $\mathrm{Ir} /$ $\mathrm{B}_{4} \mathrm{C}$ as noncarbon-based oxygen electrode. Nano. Lett. 17, 1417-1424 (2017)

53. Radin, M. D. \& Siegel, D. J. Charge transport in lithium peroxide: relevance for rechargeable metal-air batteries. Energy Environ. Sci. 6, 2370-2379 (2013).

54. Aetukuri, N. B. et al. Solvating additives drive solution-mediated electrochemistry and enhance toroid growth in non-aqueous $\mathrm{Li}-\mathrm{O}_{2}$ batteries Nat. Chem. 7, 50 (2015).

55. Wang, Y., Liang, Z., Zou, Q., Cong, G. \& Lu, Y.-C. Mechanistic insights into catalyst-assisted nonaqueous oxygen evolution reaction in lithium-oxygen batteries. J. Phys. Chem. C. 120, 6459-6466 (2016).

56. Zhang, H. et al. Electrolyte additives for lithium metal anodes and rechargeable lithium metal batteries: progress and perspectives. Angew. Chem. Int. Ed. 57, 15002-15027 (2018).

57. Zhuang, Q.-C., Li, J. \& Tian, L.-L. Potassium carbonate as film forming electrolyte additive for lithium-ion batteries. J. Power Sources 222, 177-183 (2013).

58. Kresse, G. \& Furthmüller, J. Efficient iterative schemes for ab initio totalenergy calculations using a plane-wave basis set. Phys. Rev. B 54, 11169 (1996).

59. Kresse, G. \& Furthmüller, J. Efficiency of ab-initio total energy calculations for metals and semiconductors using a plane-wave basis set. Comput. Mater. Sci. 6, 15-50 (1996).

60. Perdew, J. P., Burke, K. \& Ernzerhof, M. Generalized gradient approximation made simple. Phys. Rev. Lett. 77, 3865 (1996).

61. Henkelman, G., Uberuaga, B. P. \& Jónsson, H. A climbing image nudged elastic band method for finding saddle points and minimum energy paths. $J$. Chem. Phys. 113, 9901-9904 (2000).

\section{Acknowledgements}

This work was financially supported by the National Natural Science Foundation of China $(21871177,21673140,21720102002)$ and the Opening Project of State Key Laboratory of High Performance Ceramics and Superfine Microstructure (SKL201703SIC). J.C. and S.L.Z. acknowledged University of California, Los Angeles for the startup support. The authors thank Shanghai Synchrotron Radiation Facility for the provision of beam time (BL14W1)

\section{Author contributions}

S.M.X. and K.X.W. designed the experiment, did catalyst synthesis and characterization battery tests and DFT calculation. X.L. participated in the batteries tests. X.Y.W. helped XRD characterization and analyses. J.S.C. and K.X.W. supervised the project. S.L.Z. and J.C. contributed to the revision of the manuscript. All authors discussed the results and commented on the manuscript.

\section{Competing interests}

The authors declare no competing interests. 


\section{Additional information}

Supplementary information is available for this paper at https://doi.org/10.1038/s41467019-13712-2.

Correspondence and requests for materials should be addressed to J.C., K.-X.W. or J.-S.C.

Peer review information Nature Communications thanks Venkatasubramanian Viswanathan and the other, anonymous, reviewer(s) for their contribution to the peer review of this work. Peer reviewer reports are available.

Reprints and permission information is available at http://www.nature.com/reprints

Publisher's note Springer Nature remains neutral with regard to jurisdictional claims in published maps and institutional affiliations. (c) Open Access This article is licensed under a Creative Commons Attribution 4.0 International License, which permits use, sharing, adaptation, distribution and reproduction in any medium or format, as long as you give appropriate credit to the original author(s) and the source, provide a link to the Creative Commons license, and indicate if changes were made. The images or other third party material in this article are included in the article's Creative Commons license, unless indicated otherwise in a credit line to the material. If material is not included in the article's Creative Commons license and your intended use is not permitted by statutory regulation or exceeds the permitted use, you will need to obtain permission directly from the copyright holder. To view a copy of this license, visit http://creativecommons.org/ licenses/by/4.0/.

(C) The Author(s) 2019 